\title{
FILM DOKUMENTER “BENA NA NA PIA NA NA NA'A” PADA TRADISI MEMBANGUN RUMAH SUKU BENA
}

\author{
Fentisari Desti Sucipto ${ }^{1}$, Muchammad Rizky Kadafi ${ }^{2}$ \\ ${ }^{1}$ Desain Komunikasi Visual, Jurusan Seni Rupa dan Desain, Institut Seni Budaya Indonesia Aceh, \\ Jantho, Aceh, ${ }^{2}$ Desain Komunikasi Visual, Fakultas Ilmu Komputer, Institut Informatika dan Bisnis \\ Darmajaya, Lampung \\ E-mail: fentisaridestisucipto@isbiaceh.ac.id, mohkadavi@darmajaya.ac.id, HP: +6282143304474
}

\begin{abstract}
Bena tribe which originally from Nusa Tenggara Timur is one of the tribe that survive with its own tradition until today. One of their belief is a symbol of their house as a human. Thus, their houses have given name. Every house represents female or male. Since they start to design the house up to finalize the building process, it has 17 steps. Every step has its particular ritual, if they do mistake on the development process, Bena Belief they will experience the disaster. Their custom is never well- documented, therefore Bena $\mathrm{Na} \mathrm{Na} P \mathrm{Pia} \mathrm{Na} \mathrm{Na} \mathrm{Na'a} \mathrm{as} \mathrm{a} \mathrm{documentary} \mathrm{film} \mathrm{is} \mathrm{designed} \mathrm{as} \mathrm{a} \mathrm{visual}$ archive in the form of video. The artistic research methods using qualitative approach. The data collection used ethic and emic observation, semi structured interview, and visual recording data. The result was analyzed and interpreted as a script, then collaborated using visual data to be a documenter film which inform the ritual, belief and development process of Bena Traditional House
\end{abstract}

Keywords: Documentary Film entitled Bena, Bena builds house, bena tribe.

\section{ABSTRAK}

Suku Bena dari Nusa Tenggara Timur merupakan suku yang masih mempertahankan tradisi leluhur hingga saat ini. Salah satunya adalah kepercayaan mengenai rumah sebagai wujud perlambangan manusia. Sehingga rumah di Suku Bena mempunyai nama yang berbeda. Setiap rumah dapat mewakili kaum perempuan maupun kaum laki-laki. Sejak rumah mulai dirancang hingga selesai dibangun terdapat 17 tahapan. Setiap tahapan mempunyai ritual khusus, jika terdapat kesalahan pada ritual, suku Bena percaya bahwa akan terjadi bencana. Adat yang telah diturunkan dari satu generasi ke generasi selanjutnya terutama dalam konteks membangun rumah dengan segala macam ritual dan kepercayaannya belum pernah didokumentasikan dengan baik secara visual. Oleh karena itu film dokumenter Bena $\mathrm{Na} \mathrm{Na}$ Pia $\mathrm{Na} \mathrm{Na} \mathrm{Na'a} \mathrm{atau} \mathrm{dalam} \mathrm{bahasa} \mathrm{Indonesia} \mathrm{bermakna} \mathrm{Bena} \mathrm{mengulang} \mathrm{dan}$ menyimpan petuah leluhur secara terus menerus, dirancang sebagai arsip visual yang dapat dijadikan referensi untuk generasi berikutnya serta masyarakat luas secara umum. Metode penelitian artistik ini menggunakan pendekatan kualitatif. Pengumpulan data dilakukan dengan metode observasi emik dan etik, wawancara semi terstruktur serta pendokumentasian secara visual dalam bentuk video. Hasil yang didapat dilakukan analisis dan diterjemahkan menjadi naskah, kemudian 
dikolaborasikan dengan data visual sehingga menjadi sebuah film dokumenter yang dapat menginformasikan mengenai ritual, kepercayaan dan proses membangun rumah di suku Bena.

Kata kunci: Film Dokumenter Bena, Membangun rumah suku bena, Suku Bena

\section{PENDAHULUAN}

Kebudayaan dewasa ini merupakan pembahasan yang sering didiskusikan pada beberapa seminar antar cendikiawan yang mendalami topik tersebut. Pembahasan yang sering diulas adalah mengenai budaya lokal pada suatu daerah, revitalisasi budaya lokal dan menjaga eksistensi budaya lokal di tengah akulturasi maupun asimilasi dengan kebudayaan global. Merujuk pada hakikat kebudayaan dari Liliweri (2014) yang telah mencoba mengelaborasikan beberapa makna kebudayaan dari beberapa ahli, menurutnya kebudayaan merupakan matriks yang kompleks bermuatan interaksi dari banyak elemen. Selain itu, kebudayaan terdapat dimanapun, bersifat multidimensi, kompleks dan dapat meresap ke dalam kehidupan personal, komunikasi serta masyarakat. Pendapat ini berjalan seiiring fenomena yang ada di berbagai belahan dunia, khususnya Indonesia. Salah satu contoh sifat budaya yang meresap ke dalam kehidupan personal, komunikasi dan masyarakat adalah tradisi membangun rumah pada suku Bena.

Suku Bena berasal dari Nusa Tenggara Timur. Suku Bena merupakan suku yang masih mempertahankan tradisi leluhur hingga saat ini. Salah satunya adalah kepercayaan mengenai rumah sebagai wujud perlambangan manusia. Sehingga rumah di Suku Bena mempunyai nama yang berbeda. Setiap rumah dapat mewakili kaum perempuan maupun kaum laki-laki. Rumah yang mewakili kaum perempuan diberi nama Sao Saka Pu'u dan yang mewakili laki-laki disebut Sao Saka Lobo. Pembeda keduanya adalah tanda di atas rumah. Rumah juga dianggap bertingkah laku seperti manusia.

Proses pembangunan rumah di Suku Bena mempunyai ritual tersendiri. Ritual tersebut terdiri aras tujuh belas tahapan proses yang wajib dilakukan. Ritual tersebut ada yang melibatkan pihak tertentu ada juga yang melibatkan pihak luar hingga dapat menjadi satu tontonan atau pertunjukkan bagi pihak luar. Inilah yang menjadi salah satu daya tarik ekowisata.

Namun, tidak banyak yang mengetahui bahwa setiap ritual mempunyai syarat tertentu. Contohnya adalah menyalakan api pada tungku masak atau disebut Lika setelah rumah adat dibangun. Masyarakat Bena percaya bahwa tujuan dari menyalakan api terus-menerus untuk menjaga agar alang-alang sebagai salah satu bahan dalam membangun rumah dapat bertahan awet bahkan hingga empat puluh tahun. Masyarakat Bena juga percaya bahwa ketika ada kendala atau masalah saat pembangunan rumah, maka akar permasalahan tersebut terkait dengan ritual yang mungkin saja tidak sesuai dengan seharusnya. Sehingga solusi yang diterapkan secara 
turun menurun adalah mencari akar masalah tersebut melalui ritual lainnya.

Berdasarkan fenomena yang terjadi tersebut peniliti tertarik untuk mendokumentasikannya menjadi sebuah film dokumenter dengan tujuan memberikan informasi kepada khalayak luas mengenai kebudayaan yang ada pada Suku Bena khususnya dalam proses pembangunan rumah. Film dokumenter dipilih sebagai salah satu media yang menyampaikan fakta melalui riset yang mendalam dan melalui tiga tahapan utama pada proses perancangannya yaitu praproduksi, produksi dan pasca produksi. Konsep ini sejalan dengan pemikiran Tazi (2010) mengenai film dokumenter yang menajdi salah satu usaha untuk mencari pola dan keteraturan mengenai fenomena yang terjadi. Keteraturan atau pola tersebut kemudian dirangkai menjadi sebuah cerita menggunakan medium audio visual.

\section{STUDI LITERATUR}

Setelah melakukan identifikasi pada topik film dokumenter, suku Bena, dan arsip visual, peneliti melakukan tinjauan pustaka. Berdasarkan Cooper dkk dalam Cresswell (2016;36) tujuan utama dari tinjauan pustaka adalah memberikan informasi kepada para pembaca mengenai hasil penelitianpenelitian lain yang mempunyai kaitan erat dengan penelitian yang sedang dilakukan, menjadi jembatan penghubung penelitian dengan literatur yang telah ada, dan mengisi kemungkinan adanya celah dari pada peneltian sebelumnya.

Osin, Kusuma dan Suryawati (2019) dalam jurnal berjudul Strategi Pengembangan Objek Wisata Kampung Tradisional Bena Kabupaten Ngada Flores NTT menjelaskan bahwa wisata budaya dan seni arsitektur tradisional suku Bena sudah pada bidang arsitektur, upacara adat, seni mengukir kayu dan kerajinan tenun ikat tradisional. Penelitian ini mempunyai kesamaan dalam hal objek yang diamati yaitu kampung wisata Bena, namun perbedaannya adalah output dari penelitian yang diterapkan oleh penulis adalah visual dalam bentuk film dokumenter.

Jurnal dengan topik Praktik Ekowisata di Kampung Tradisional Bena yang ditulis oleh Amtiran dan Suryawan (2016) menjelaskan bahwa Kampung Bena menerapkan praktik ekowisata yang melibatkan masyarakat secara penuh dalam merencanakan, melaksanakan serta mengelola kampung tradisional Bena. Dampak positif dari penerapan ini bagi masyarakat Bena dapat secara praktis dirasakan terutama dari segi ekonomi. Salah satu contoh dari keterlibatan optimal masyarakat terhadap segala proses ekowisata adalah pembangunan rumah adat suku Bena dimana terdapat unsur gotong royong mulai dari upacara adat, penebangan pohon, penanaman tiang rumah hingga pemasangan atap. Selain itu, setiap suku yang ada di kampung Bena menyumbangjan hewan untuk disembelih sebagai korban dalam upacara maupun bahan makanan selama pembangunan rumah adat dilakukan. Jurnal ini mempunyai kesamaan objek penelitian yaitu kampung ekowisata Bena, namun hasil akhir penelitiannya berbeda dengan yang penulis lakukan, karena penulis merancang film dokumenter.

Menurut Setiawan dan Triono (2015) pada jurnal yang berjudul Pembuatan Film Dokumenter "Bukan Gangster" Melalui Implementasi Teknik Pengambilan Gambar dan Teknik 
Editing Pada Komunitas Motor Sobbisco Karanganyar, mencoba untuk mengklarifikasi dan melakukan edukasi terhadap masyarakat mengenai perbedaan antara geng motor dan komunitas motor. Film dokumenter tersebut menggunakan software Sony Vegas Pro 10 dan Cool Edit Pro. Spesifikasi perangkat keras yang digunakan adalah monitor samsung 19", processor AMD Phenom II X2, RAM 2GB, Hard Disk 500 GB, Keyboard Multimedia komic, drive dvd room, mouse logitech, dan speaker simbada CST 6100 N. Artikel ini mempunyai kesamaan dalam hal merancang film dokumenter akan tetapi berbeda dalam hal spesifikasi alat yang digunakan dan topik yang diambil dalam film. Penulis mengambil topik proses menjaga tradisis membangun rumah di Suku Bena.

Mubarik, Buda dan Dwiyani (2018) menjelaskan bahwa film dokumenter sebagai salah satu media informasi khususnya kerukunan beragama di Bali. Film "Nyama Selam" memiliki tiga struktur cerita yaitu awal untuk menceritakan mengenai sejarah Islam di Candikuning dan Bali. Bagian tengah menceritakan tradisi, toleransi dan makna frasa nyama selam. Bagian akhir menjelaskan mengenai harapan dari narassumber mengenai pentingnya toleransi dan kerukunan beragam di Bali. Pada pembuatan film ini terdapat tiga tahapan yaitu praproduksi, produksi dan pasca produksi. Metode yang digunakan untuk mengumpulkan data adalah observasi dan wawancara. Hasil penelitian ini berbeda dengan apa yang penulis dapatkan karena objek yang diteliti juga berbeda. Namun mempunyai kemiripan dalam hal metode dan tahapan merancang.
Perkasa dan Sayatman (2015) pada jurnal yang berjudul Perancangan Film Dokumenter Kawasan Purbakala Gunung Penanggungan menjelaskan bahwa film dokumenter menjadi salah satu cara kreatif untuk menyajikan informasi, terutama mengenai gunung Penanggungan. Metode untuk merancang konten dilakukan melalui observasi lapangan, studi literatur dan juga wawancara yang selanjutnya diolah menjadi naskah cerita. Informasi penting yang disampaikan pada film ini adalah mengenai gunung penanggungan secara umum dan informasi sejarah serta budaya disekitar gunung penanggungan. Tahapan pada proses pembuatan film dokumenter terdapat tiga seperti pada artikel sebelumnya yaitu pra produksi, produksi dan pasca produksi. Persamaan antara penelitian ini dengan yang penulis rancang adalah samasama memproduksi film dokumenter dengan tujuan yang serupa yaitu memberikan informasi pada khalayak luas mengenai objek tertentu. Sedangkan perbedaannya ada pada objeknya.

\section{METODE}

Pendekatan yang digunakan pada penelitian artistik ini adalah pendekatan kualitatif. Menurut Cresswell (2016;24), pendekatan kualitatif adalah usaha untuk membangun makna mengenai suatu fenomena yang berdasarkan pada pandangan-pandangan dari para partisipan. Pendekatan kualitatif pada penelitian ini berusaha untuk mengelaborasikan berbagai pandangan dari masyarakat Suku Bena mengenai tradisi membangun rumah.

Proses perancangan film dokumenter memerlukan metode yang tepat sesuai dengan tahapan 
produksinya sendiri yaitu praproduksi, produksi dan pasca produksi. Tahapan pra-produksi bertujuan untuk meriset data sehingga menjadi naskah produksi. Setelah naskah produksi tertata rapi maka akan dilakukan proses produksi yaitu penyusunan visual yang telah didapatkan. Tahap pasca produksi adalah tahapan editting agar hasil visual dan audio dapat dikatakan layak untuk dipertontonkan di khalayak umum.

Meriset untuk menjadikan naskah yang mampu menggambarkan kejadian sebenarnya sesuai dengan kenyataan di lapangan diperlukan metode tersendiri. Pada penelitian artistik ini, metode yang digunakan adalah wawancara kepada beberapa narasumber dan juga melakukan observasi etik serta emik. Observasi etik dilakukan oleh peneliti saat peneliti menjadi penonton pada ritual yang dilakukan oleh Sukku Bena, sedangkan observasi etik dilakukan peneliti saat peneliti menjadi bagian dari ritual tersebut.

\section{HASIL DAN PEMBAHASAN}

Film dokumenter berjudul Bena $\mathrm{Na} \mathrm{Na}$ Pia $\mathrm{Na} \mathrm{Na} \mathrm{Na}^{\prime} a$ berarti Bena mengulang dan menyimpan petuah leluhur secara terus menerus. Film ini menceritakan mengenai Suku bena yang merupakan suku yang terletak di dalam wilayah desa Tiworiwu, Kecamatan Jerebu'u, Kabupaten Ngada, Flores provinsi Nusa Tenggara timur dan secara geografis berada pada sebuah lembah di antara dua buah gunung yaitu Gunung Inerie dan Surolaki serta dikelilingi panorama pemandangan dan perbukitan Jerebu'u. Suku ini menjadi salah satu tujuan wisata untuk melihat desa megalitikum yang masih ada hingga saat ini. Dalam film ini akan digambarkan situasi dan bagaimana suku Bena menerapkan ritual dalam membangun rumah adat. Terdapat 17 ritual yang wajib dijalankan oleh suku Bena, jika tidak mereka percaya bahwa akan terjadi hal buruk yang tidak dapat diprediksi. Sehingga, fungsi ritual pada suku bena bukan saja sebagai sebuah atraktsi melainkan jauh lebih dalam dan sakral daripada itu, yaitu menjaga keselamatan.

Naskah pada film ini dibagi menjadi tiga bagian atau segment. Pertama sebagai pengenalan mengenai Suku Bena, kepercayaan dan rumah adatnya. Bagian kedua menarasikan tujuh belas ritual dan akibatnya jika tidak dilakukan. Bagian ketia atau penutup, berisi pesan moral dari kepercayaan suku Bena. Pesan moral tersebut berbunyi 'Begitulah cara suku Bena menjaga satu sama lain. Bagi suku Bena, menjaga ritual bukan hanya sekedar melestarikan budaya. Melainkan lebih daripada itu. Menjaga ritual adalah satu cara mengingat ajaran leluhur. Menjaga ritual adalah menjaga keseimbangan antara alam dan manusia. Menjaga ritual adalah menjaga keluarga dari bahaya.'

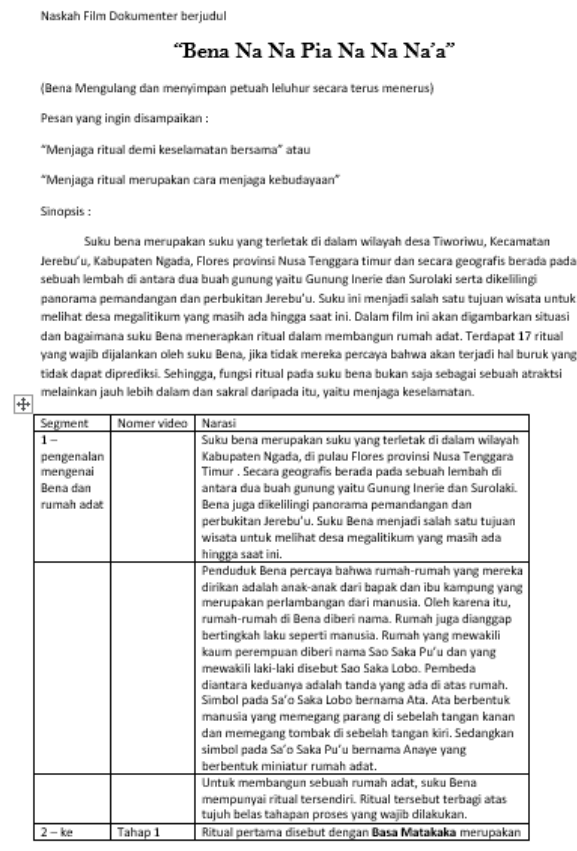


Gambar 1 : Draft naskah film dokumenter Bena Na Na Pia Na Na Na'a

Sumber : dokumen pribadi penulis. 2020

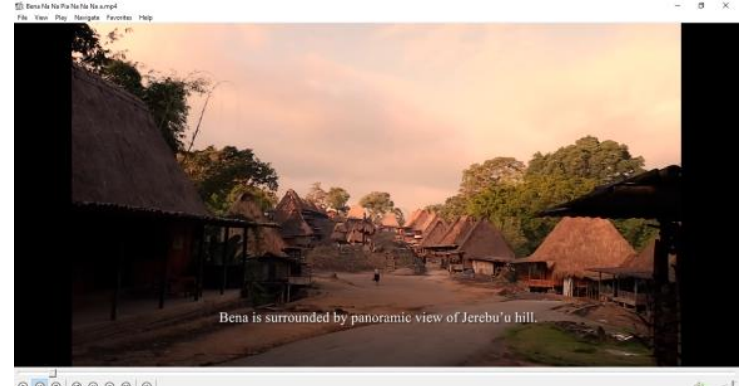

Gambar 2 : Screenshot bagian pertama Bena berdasarkan draft naskah

Sumber : dokumen pribadi penulis. 2020

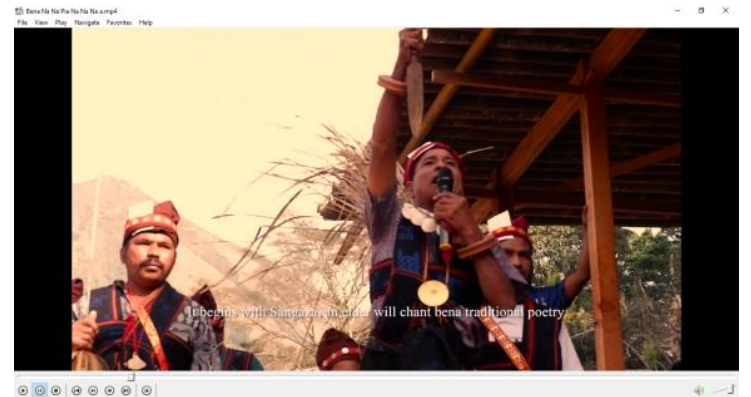

Gambar 3 : Screenshot bagian kedua Bena berdasarkan draft naskah

Sumber : dokumen pribadi penulis. 2020

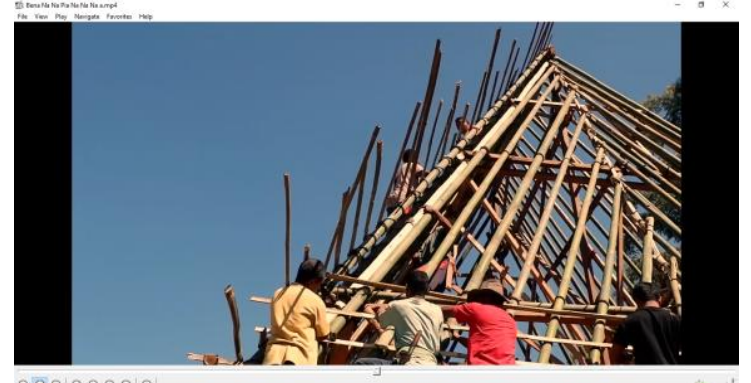

Gambar 4 : Screenshot bagian kedua Bena berdasarkan draft naskah

Sumber : dokumen pribadi penulis. 2020

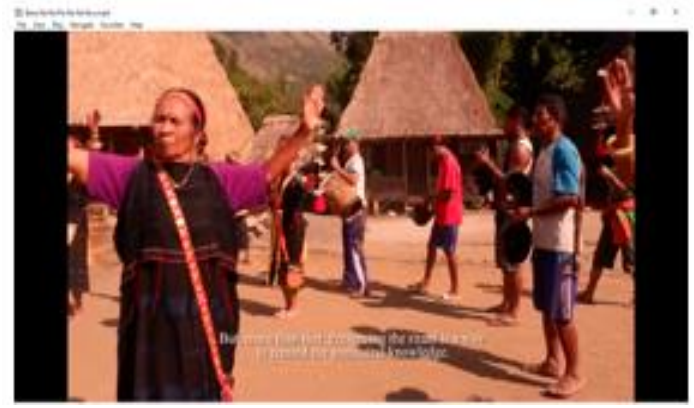

Gambar 5 : Screenshot bagian ketiga Bena berdasarkan draft naskah

Sumber : dokumen pribadi penulis. 2020

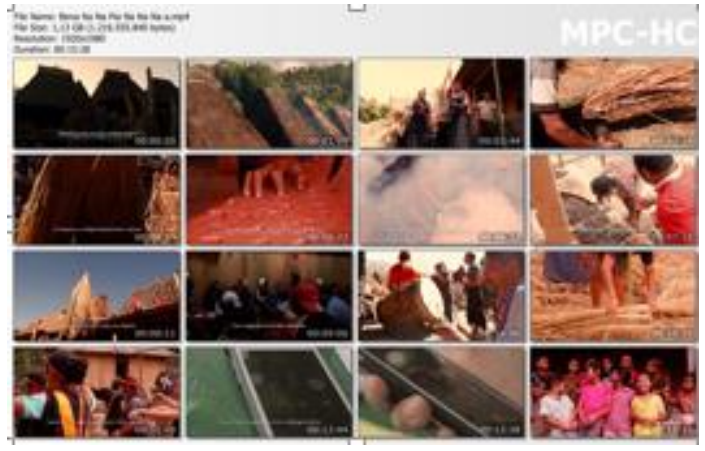

Gambar 5 : Thumbnail keseluruhan film dokumenter Bena Na Na Pia Na Na Na'a Sumber : dokumen pribadi penulis. 2020

Durasi pada film dokumenter Bena Na Na Pia Na Na Na'a adalah 15 menit 27 detik dengan format file .mp4 - Setiap frame yang terdapat narasi berupa audio diberikan subtitle dalam bahasa Inggris. Tujuannya agar informasi yang ada pada setiap narasi yang diucapkan dalam bahasa Indonesia dapat dipahami oleh masyarakat yang bukan berasal dari Indonesia saja. Hal ini berlandaskan pada hasil observasi di lapangan bahwasannya penonton atau penikmat pertunjukkan ritual suku Bena bukan hanya wisatawan lokal melainkan mancanegara.

Beberapa atribut film dapat dikategorikan menjadi beberapa bagian yaitu ilustrasi, infografis dan audio. Ilustrasi yang disajikan pada setiap frame film berlandaskan pada hasil observasi fenomena membangun rumah beserta ritual serta perspektif masyarakat suku Bena. Infografis pada frame lebih diutamakan pada bagian judul yaitu di frame awal film dan credit tittle atau bagian akhir film yang memuat semua tim produksi film. Audio yang terdapat pada film ada dua macam yaitu narasi dan musik. Narasi film menceritakan dan menjelaskan sesuai dengan naskah. Sedangkan musik diambil dari musik tradisional Suku Bena saat memainkannya di ritual. 
Film dokumenter pada dasarnya mempunyai beberapa fungsi yang terkait dengan tujuan perancangan film itu sendiri. Film dokumenter Bena $\mathrm{Na}$ $\mathrm{Na} P$ ia $\mathrm{Na} \mathrm{Na} \mathrm{Na'a} \mathrm{mempunyai} \mathrm{fungsi}$ sebagai arsip visual ritual suku Bena saat membangun rumah dengan berbagai macam ritual dan juga pandangan masyarakat mengenai dampak jika terdapat kesalahan saat proses pembangunan. Sehingga tujuan dari film ini adalah sebagai sarana informasi secara visual mengenai budaya suku tertentu, dalam konteks ini adalah suku Bena. Selain itu, film ini dapat menjadi salah satu referensi visual yang ikut serta dalam melestarikan kebudayaan suku Bena di era derasnya arus informasi.

\section{KESIMPULAN}

Film dokumenter dapat menjadi salah satu alternatif media kreatif dalam memvisualkan suatu kebudayaan. Pada penelitian artistik ini, subjek yang diangkat adalah tradisi suku Bena terutama dalam hal ritual membangun rumah. Rumah merupakan kebutuhan pokok yang sudah ada sejak lama. Rumah pula yang menjadi tempat berlindung dari bencana serta tempat untuk tinggal dalam waktu yang lama. Melalui film ini dapat diketahui bahwa makna rumah bagi suku Bena bukan hanya tempat untuk tidur maupun makan, melainkan juga berkumpul dengan keluarg. Bahkan, pada proses pembangunan rumah terdapat nilai gotong royong dari para masyarakat sekitar serta bagaimana suku Bena tetap menjaga serta melestarikan suatu kebudayaan yang telah ada sejak ratusan tahun yang lalu hingga saat ini menjadi salah satu destinasi wisata yang bukan hanya didatangi olehh wisatawan lokal tapi juga mancanegara. Sikap keterbukaan terhadap dunia namun tetap menjaga warisan budaya menjadi kekuatan suku Bena untuk bertahan dalam pusaran globalisasi.

\section{DAFTAR PUSTAKA}

Amtiran, Muni Imelda dan Suryawan, Ida Bagus. 2016. Praktik ekowisata di Kampung Tradisional Bena, Desa Tieoriwu Kabupaten Ngada, Provinsi Nusa Tenggara Timur. Jurnal Destinasi Wisata Vol. 4 No. 2 Hal. 100-102Liliweri, Alo. 2014. Pengantar Studi Kebudayaan. Bandung : Penerbit Nusa Media

Cresswell, John. 2016. Research Design : Pendekatan Metode Kualitatif, Kuantitatif dan Campuran.

Gugat, Topan Dewa; Sulaiman dan Nazar Sahrul. 2019. Penciptaan Film "Wayang Padang" dengan Pendekatan French New Wave.

Mubarik, Hanif Syahrul; Buda, I Ketut; Dwiyani, Ni Kadek. 2018. Film Dokumenter "Nyama Selam" dengan Gaya Expository. Jurnal Prabangkara Vol.22 No.1 Hal 23-30

Osin, Rosvita Flaviana; Kusuma, Irawinne Rizky Wahyu; Suryawati, Dewa Ayu. 2019. Strategi Pengembangan Objek Wisata Kampung Tradisional Bena Kabupaten Ngada-Flores Nusa Tenggara Timur (NTT). Jurnal Undhira Vol. 14 No. 1 Hal. 60-65

Perkasa, Huda dan Sayatman. 2015. Perancangan Film Dokumenter Kawasan Purbakala Penanggungan.

Setiawan, Taufiq Yuliana dan Triono, Ramadhan Agus. 2015. Pembuatan Film Dokumenter "Bukan Gangstre" Melalui 
Implementasi Teknik

Pengambilan Gambar dan

Teknik Editing pada Komunitas

Motor Sobbisco Karanganyar.

Jurnal Speed Vol. 7 No. 1 Hal 16-22

Sucipto, Fentisari Desti. 2017. Persepsi

Pemangku Kepentingan

Eksternal Yogyakarta

Terhadap Jenama "Jogja

Istimewa". Jurnal Aksa Vol.

No.1 